\title{
Effects of Different Water Seasons on the Residual Characteristics and Ecological Risk of Polycyclic Aromatic Hydrocarbons in Sediments from Changdang Lake, China
}

\author{
Javid Hussain, ${ }^{1}$ Zhenhua Zhao, ${ }^{1,2,3}$ Yong Pang, ${ }^{1}$ Liling Xia, ${ }^{3}$ \\ Ittehad Hussain, ${ }^{4}$ and Xin Jiang ${ }^{2}$ \\ ${ }^{1}$ Key Laboratory of Integrated Regulation and Resource Development on Shallow Lake of Ministry of Education, \\ College of Environment, Hohai University, Nanjing 210098, China \\ ${ }^{2}$ State Key Laboratory of Soil and Sustainable Agriculture (Institute of Soil Science, Chinese Academy of Sciences), \\ Nanjing 210098, China \\ ${ }^{3}$ State Key Laboratory of Pollution Control and Resource Reuse, Nanjing University, Nanjing 210046, China \\ ${ }^{4}$ College of Energy and Environment, Southeast University, Nanjing 210096, China
}

Correspondence should be addressed to Zhenhua Zhao; zzh4000@126.com and Yong Pang; pangyong@hhu.edu.cn

Received 21 October 2015; Revised 19 December 2015; Accepted 22 December 2015

Academic Editor: Jun Wu

Copyright (C) 2016 Javid Hussain et al. This is an open access article distributed under the Creative Commons Attribution License, which permits unrestricted use, distribution, and reproduction in any medium, provided the original work is properly cited.

\begin{abstract}
The sediments' samples were collected from Changdang Lake for the concentration of fourteen polycyclic aromatic hydrocarbons in March (dry season), June (wet season), and September (temperate season) 2013. The highest average value of $\sum$ PAHs was detected as $295.28 \mathrm{ng} / \mathrm{g} \mathrm{dw}$ in March, followed by $240.91 \mathrm{ng} / \mathrm{g} \mathrm{dw}$ in June and $165.81 \mathrm{ng} / \mathrm{g} \mathrm{dw}$ in September. Source characterization studies based on the analysis of diagnostic ratio (triangular plot method) suggested that the PAHs in sediments from Changdang Lake were mainly from the mixed combustion source of biomass and petroleum, and the origins of PAHs in different sampling sites have a great deal of temporal and spatial variability during different water seasons. Redundancy analysis was applied to identify the impact factors and the possible relationship between PAHs and environmental parameters. The predicted results showed that the main factors impacting PAHs temporal distribution were temperature, dissolved oxygen, $\mathrm{pH}$, and oxidation-reduction potential, while conductivity showed secondary impacts on the PAHs distribution. Risk assessment of PAHs in sediments was carried out based on the US Sediments Quality Guidelines (SQGs). By comparing the present study results with SQGs standard values results showed that the adverse effects are not expected at the present levels of PAHs contamination observed in the sediments from Changdang Lake.
\end{abstract}

\section{Introduction}

Polycyclic aromatic hydrocarbons (PAHs) are a major group of persistent organic pollutants and mainly produced by anthropogenic activities [1-3]. Anthropogenic sources of PAHs are of two types, petrogenic and pyrogenic. Petrogenic PAHs are generated from petroleum and its products which are entered into aquatic environments through oil spills, accidental leakages of marine and land pipelines, and domestic and industrial wastes [4-6]. Pyrogenic PAHs, which are common in aquatic environment, are generated through incomplete combustion of organic matter (e.g., coal, petroleum, and wood) and give rise to complex mixtures of PAHs with 4-6 rings that include fluoranthene (Fla), pyrene (Pyr), benzo[a]anthracene $(\mathrm{BaA})$, chrysene (Chy), benzo[b]fluoranthene $(\mathrm{BbF})$, benzo[k]fluoranthene $(\mathrm{BkF})$, benzo[a]pyrene $(\mathrm{BaP})$, dibenzo[a,h] anthracene (DahA), benzo[g,h,i]perylene (BghiP), and indeno[1,2,3,(c,d)]pyrene (InP) [7, 8]. Pyrogenic sources are regarded as more thermodynamically stable and toxic than petrogenic sources due to their high concentrations of nonalkylated PAHs [9-11]. A water body can act as a major sink for PAHs [12] and can be influenced by wet and dry deposition [13].

PAHs can be incorporated into the food web, but PAHs ultimately accumulate in sediments. However, this process can be reversed when the equilibrium between sediments 
and the overlying water body is interrupted, in which case sediments highly contribute toxic PAHs compounds to the food web resulting in fundamental alterations of the ecosystems that may affect the human body $[14,15]$. Due to their carcinogenic and mutagenic effects on both terrestrial and aquatic organisms [16], the distribution and sources of PAHs have gathered significant environmental concern $[17,18]$. Their potentially hazardous properties and persistence in the environments prompted the United States Environmental Protection Agency (USEPA) to include 16 PAHs within the priority pollutants list [19].

The US EPA and International Agency for Research on Cancer (IARC) classify seven PAHs (benzo[a]pyrene, benzo[a] anthracene, chrysene, benzo[b]fluoranthene, benzo[k] fluoranthene, dibenzo[a,h]anthracene, and indeno[1,2,3cd]pyrene) as possible human carcinogens (USEPA Class B2). Other PAHs may also cause carcinogenic effects and should not be considered as noncarcinogens [22]. PAHs affect cell division, cause tumors, and alter reproduction rates through enzymes induction process $[23,24]$.

Source identification of PAHs has been a hot research topic and challenging field for the domestic and foreign scientists. Ratios of PAHs are often used to be accurate and reliable diagnostic tools for sources identification of PAHs $[25,26]$. As isomers of PAHs have similar thermodynamic and kinetic characteristics and isomers from the same source undergo the same transformation process, the ratio of different PAHs can determine the type of pollution sources [26]. But when using a single ratio of PAHs for the source identification, it may result in an inaccurate estimate of PAH source; in order to avoid this situation, we innovatively proposed a source identification method of PAHs using three kinds of diagnostic ratios of PAHs in a triangular plot. The ratio of low molecular weight and high molecular weight PAHs $(\mathrm{L} / \mathrm{H})$ and isomers are commonly used as a ratio method [27]. These groups of compounds are of molecular weights 178 (phenanthrene and anthracene), 202 (fluoranthene and pyrene), 228 (benzo[a] anthracene and chrysene), and 276 (indeno[1,2,3-cd]pyrene and benzo[g,h,i]perylene). In the present study, the ratios of Ant/(Ant + Phe $),$ Fla/(Fla + Pyr $)$, and $\mathrm{BaA} /(\mathrm{BaA}+\mathrm{Chr})$ were used to identify the PAHs sources in sediment.

The environmental parameters included in this study (temperature, $\mathrm{pH}$, dissolved oxygen, oxidation-reduction potential, and $\mathrm{pH}$ ) are variables which are believed to affect the PAHs residual characteristics differing from site to site and regulate the process of biodegradation. The relationship between environmental parameters and PAHs was investigated through redundancy analysis (RDA) which was first proposed by Rao [28].

This analysis method has been used by some researchers in geochemical studies and source analyses [29, 30]. The CANOCO 4.5 software bundled with CanoDraw for Windows was used to perform redundancy analysis [31-33]. In previous studies, this software was used to investigate aliphatic hydrocarbon composition, thereby partitioning various petroleum sources (wastewater irrigation, oil wells, and atmospheric deposition) into different groups [34].
Ecological risk of PAHs was assessed by the United States "Sediment Quality Guidelines" (SQGs) which is a useful approach to assess the sediments with a ranking of lesser to greater impacts. SQGs provide a scientifically justifiable basis for assessing the potential effects of sediment-associated contaminants on aquatic organisms [35-37]. PAHs risk assessment has been reported in several studies in different regions of the world $[38,39]$. However, due to the complex nature of sediments and the fact that risk assessment for PAHcontaminated sediments requires an estimate of the toxicity to aquatic organisms of the complex PAHs assemblage in the sediments, it is difficult to find out the exact potential impacts posed by PAHs in sediments [40].

This study aims to explore the effects of different water seasons on the distribution of PAHs, to identify the possible sources, and to conduct an ecological risk assessment to recognize the possible adverse ecological effects of PAHs in sediments from Changdang Lake.

\section{Materials and Methods}

2.1. Study Area Description. Changdang Lake is located about nine kilometers away from the south of Jintan City, China. Jintan has a maritime monsoon climate, a mild and humid climate with distinct seasons. The annual average temperature is around $17^{\circ} \mathrm{C}$. The so-called Meiyu season meaning "humid and rainfall abundant" in China lasts about 2-4 weeks. Jintan is crisscrossed by numerous rivers, canals, and lakes and the water surface area occupies one-fifth of its size of the land. The natural resources mainly include salt, coal, and granite mines.

Changdang Lake covers 8,200 hectares (32 sq mi). It is one of the ten largest freshwater lakes in Jiangsu province. It has always been an important source of drinking water supply in Jintan City. Maximum depth of lake is $1.31 \mathrm{~m}$ with average depth of $1.10 \mathrm{~m}$ and its storage capacity is about $0.98 \times 108 \mathrm{~m}^{3}$.

Changdang Lake receives water from the west Xuebu River, Sudou River and flows into Taihu Lake through Huangli River, Beigan River, and Zhonggan River, which lie to the east of the lake. Figure 1 illustrated the locations of sampling sites in Changdang Lake. Sites \#1, \#2, and \#3 were selected from the northeast shore to the center of the lake; site \#4 is the main outlet to Huangli River, while sites \#5 and \#6 were selected near the inlet from Xuebu River.

2.2. Sample Collection and Pretreatment. Surface sediment $(0-20 \mathrm{~cm})$ samples were collected from six sites in Changdang Lake using stainless steel grab sampler in March (dry season), June (wet season), and September (temperate season) 2013. Each sediment sample consisted of central parts of 5 subsamples randomly collected at 5 points within the sampling area. And each sampling site was positioned by using GPS to ensure the consistency of sampling location. After collection, samples were kept in aluminum trays, dried in the shade, cleaned from impurities, and ground. Dried sediments were sieved through $100 \mu \mathrm{m}$ meshes stainless steel sieves with mechanical shaking (100 rpm, $60 \mathrm{~min})$. The mechanical shaker used was throw-action sieving where the vertical throwing motion was overlaid with slight circular 


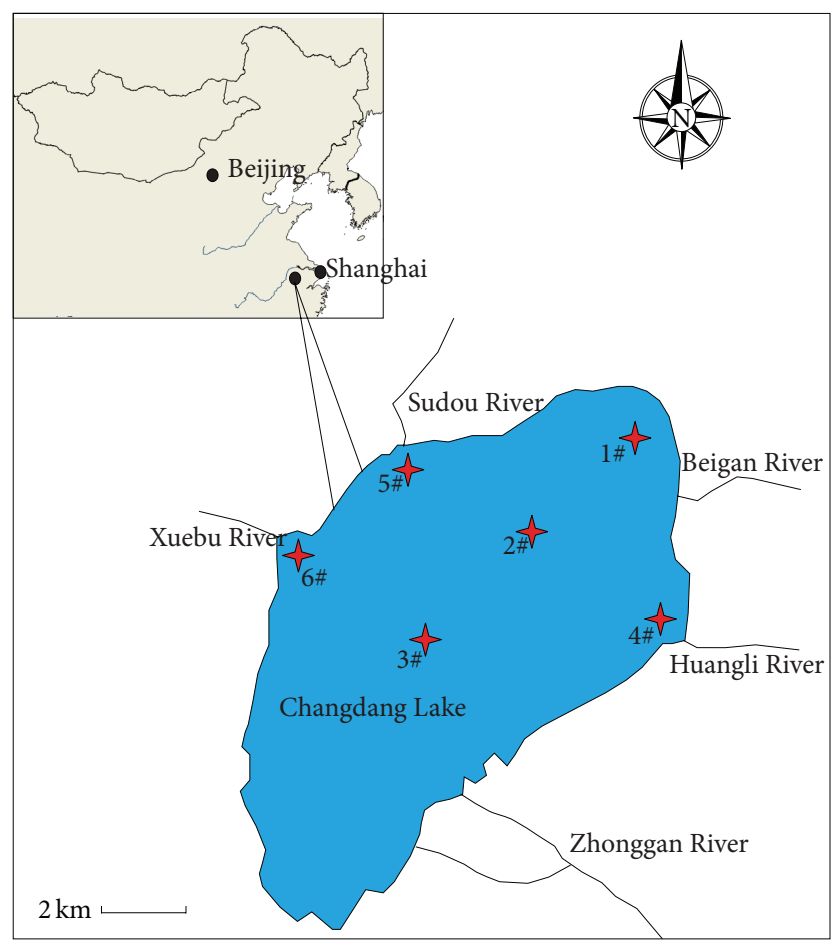

Figure 1: Study area map showing sampling sites in Changdang Lake.

motion, which helped the particles to distribute over and fall back as well to interact with the sieve mesh and pass through the opening if the particles were sufficiently small. After sieving, samples were stored in brown glass bottles and sealed by film. Several reagents were used in the analysis: the petroleum ether, acetone, hexane, methanol, and copper powders were analytical grade reagents; anhydrous sodium sulfate was guaranteed grade reagent (Nanjing Chemical Reagent Limited Company, Nanjing, China). Methylene chloride was pesticide residue level (China Chemical Reagent Limited Company, Shanghai, China). Neutral alumina was chromatographically pure (Shanghai Ludu Chemical Reagent Plant, Shanghai, China); C18-bonded silica gel and nonbonded silica gels were chromatographically pure (Dalian Institute of Chemical and Physics, Dalian, China). After the addition of anhydrous sodium sulfate, neutral alumina and silica gel were baked for $3 \mathrm{~h}$ at $400^{\circ} \mathrm{C} ; 3 \%$ distilled water was then added for deactivation. Neutral alumina and silica gel were placed in a desiccator to cool to room temperature, after which they were preserved in hermetically sealed containers.

2.3. Extraction and Purification of Samples. Three equal parts of $5 \mathrm{~g}$ sediment samples for each site were weighed; each of $5 \mathrm{~g}$ sediments sample was put into $50 \mathrm{~mL}$ glass centrifuge tube and mixed with $2.0 \mathrm{~g}$ anhydrous sodium sulfate. $15 \mathrm{~mL}$ of acetone/petroleum ether $(\mathrm{v} / \mathrm{v}=1 / 2)$ was used as extracting agent to soak the sediment samples for $1 \mathrm{~h}$ and ultrasonicextracted for 10 minutes, and then the supernatant was transferred into pear-shaped bottle. The above process was repeated twice, combining the supernatants together. At last, the extract liquid was concentrated to about $1 \mathrm{~mL}$ under $40^{\circ} \mathrm{C}$ with vacuum rotary evaporator for purifying.
The Solid Phase Purification Column (SPPC) was obtained by filling $0.5 \mathrm{~g}$ copper powder and $1 \mathrm{~g}$ anhydrous sodium sulfate in the upper layer, $1 \mathrm{~cm}$ of silica gel in the middle, and $1 \mathrm{~cm}$ of alumina pretreated in the bottom in a $6 \mathrm{~mL}$ empty column. After the SPPC was rinsed and activated with $5 \mathrm{~mL}$ petroleum ether, the concentrated extracting liquor was moved into the SPPC; then $15 \mathrm{~mL}$-hexane and $10 \mathrm{~mL}$ dichloromethane were used to elute. The eluent was collected into pear-shaped bottles, concentrated to about $1 \mathrm{~mL}$ with vacuum rotary evaporator, and finally the volume was adjusted to $1 \mathrm{~mL}$ with $\mathrm{n}$-hexane for determination.

2.4. Chromatographic Conditions. All sediments samples were analyzed for fourteen PAHs congeners, according to the US EPA standard test method (1979), by Agilent1100 HPLC with fluorescence and UV-adsorption detector (Agilent Technologies, Palo Alto, USA). A $250 \mathrm{~mm} \times 4.6 \mathrm{~mm} \times$ $5 \mu \mathrm{m}$ reversed-phase C18 column (Agilent ZORBAX Eclipse XDB-C18) served as the stationary phase. Mixed solution of acetonitrile and ultrapure water was delivered as the mobile phase in a gradient program at $0.75 \mathrm{~mL} / \mathrm{min}$. The initial volume ratio of acetonitrile and water was $60: 40$, and then the ratio of organic phase was increased to $100: 0$ till 60 minutes. PAHs were quantified by using external standard solutions obtained from Ehrenstorfer (Augsburg, Germany). Data was statistically analyzed using the Kruskal-Wallis test at $P<0.05$.

Detection of wavelength was carried out: time programming with FLD signals, 0 9 min: $\lambda_{\mathrm{Ex}}=260 \mathrm{~nm}, \lambda_{\mathrm{Em}}=$ $380 \mathrm{~nm}$; 9 16 min: $\lambda_{\mathrm{Ex}}=260 \mathrm{~nm}, \lambda_{\mathrm{Em}}=340 \mathrm{~nm} ; 16 \sim 18 \mathrm{~min}$ : $\lambda_{\mathrm{Ex}}=260 \mathrm{~nm}, \lambda_{\mathrm{Em}}=380 \mathrm{~nm} ; 18 \sim 21 \mathrm{~min}: \lambda_{\mathrm{Ex}}=260 \mathrm{~nm}$, $\lambda_{\mathrm{Em}}=380 \mathrm{~nm} ; 21 \sim 23 \mathrm{~min}: \lambda_{\mathrm{Ex}}=289 \mathrm{~nm}, \lambda_{\mathrm{Em}}=462 \mathrm{~nm}$; 23 30 min: $\lambda_{\mathrm{Ex}}=320 \mathrm{~nm}, \lambda_{\mathrm{Em}}=380 \mathrm{~nm}$; 30 36 min: $\lambda_{\mathrm{Ex}}=$ $266 \mathrm{~nm}, \lambda_{\mathrm{Em}}=403 \mathrm{~nm}$; $36 \sim 52 \mathrm{~min}: \lambda_{\mathrm{Ex}}=294 \mathrm{~nm}, \lambda_{\mathrm{Em}}=$ $430 \mathrm{~nm}$; $52 \mathrm{~min}: \lambda_{\mathrm{Ex}}=290 \mathrm{~nm}, \lambda_{\mathrm{Em}}=500 \mathrm{~nm}$. The investigated fourteen PAHs in this study included naphthalene (Nap), phenanthrene (Phe), anthracene (Ant), fluorene (Flu), fluoranthene (Fla), pyrene (Pyr), acenaphthylene (Ace), chrysene (Chr), benzo[a]anthracene (BaA), benzo[b]fluoranthene $(\mathrm{BbF})$, benzo[k]fluoranthene $(\mathrm{BkF})$, benzo[a]pyrene $(\mathrm{BaP})$, dibenzo[a,h] anthracene (DahA), and benzo[g,h,i]perylene (BghiP).

2.5. Data Analysis. To explore the relationship between PAHs and environmental parameters, redundancy analyses (RDA) were performed using CANOCO 4.5 software (Microcomputer Power, Ithaca, USA). CANOCO 4.5 is a software package for multivariate data analysis and visualization, with an emphasis on dimension reduction (ordination), regression analysis, and combination of the two, constrained ordination. Ordination triplot was drawn using CanoDraw (Microcomputer Power, Ithaca, USA). By comparing the RDA ordination results based on this technique, the predominant environmental parameters and the dominant residual PAHs at different sampling sites were determined as shown in Figure 5.

2.6. Quality Control. In order to ensure the accuracy and precision of experimental data, replicate samples, certified reference materials HS-5 (sediments, provided by NRC-IMB of 
TABLE 1: Environmental parameters measured in Changdang Lake during the study period.

\begin{tabular}{|c|c|c|c|c|c|c|c|c|c|c|c|c|c|c|c|}
\hline \multirow[t]{2}{*}{ Sampling sites } & \multicolumn{3}{|c|}{$\begin{array}{l}\mathrm{T} \\
{ }^{\circ} \mathrm{C}\end{array}$} & \multicolumn{3}{|c|}{$\begin{array}{c}\mathrm{DO} \\
\mathrm{mg} / \mathrm{L}\end{array}$} & \multicolumn{3}{|c|}{$\begin{array}{l}\text { COND } \\
\mu \mathrm{s} / \mathrm{cm}\end{array}$} & \multicolumn{3}{|c|}{$\begin{array}{c}\text { ORP } \\
\mathrm{mv}\end{array}$} & \multicolumn{3}{|c|}{$\mathrm{pH}$} \\
\hline & March & June & Sep & March & June & Sep & March & June & Sep & March & June & Sep & March & June & Sep \\
\hline$\# 1$ & 13.2 & 29.1 & 23.5 & 3.7 & 5.7 & 4.4 & 363.0 & 287.0 & 279.0 & 56.0 & 104.0 & 93.0 & 8.8 & 8.3 & 7.6 \\
\hline$\# 2$ & 14.7 & 28.8 & 25.5 & 4.1 & 8.6 & 4.7 & 326.0 & 290.0 & 468.0 & 63.0 & 85.0 & 77.0 & 8.9 & 8.8 & 7.9 \\
\hline$\# 3$ & 13.6 & 27.8 & 22.8 & 3.8 & 7.9 & 6.3 & 389.0 & 316.0 & 480.0 & 67.0 & 89.0 & 75.0 & 8.8 & 8.8 & 8.4 \\
\hline$\# 4$ & 13.1 & 27.5 & 23.1 & 6.8 & 6.0 & 5.5 & 336.0 & 316.0 & 422.0 & 73.0 & 120.0 & 90.0 & 8.7 & 8.5 & 8.2 \\
\hline$\# 5$ & 13.2 & 28 & 24.5 & 7.3 & 7.9 & 5.4 & 360.0 & 242.0 & 460.0 & 65.0 & 95.0 & 95.0 & 8.7 & 8.9 & 8.5 \\
\hline \#6 & 14.2 & 26.2 & 23.4 & 7.0 & 5.8 & 5.4 & 378.0 & 197.0 & 487.0 & 62.0 & 181.0 & 92.0 & 8.7 & 7.7 & 8.4 \\
\hline Mean & 13.7 & 27.9 & 23.8 & 5.4 & 7.0 & 5.3 & 358.7 & 274.6 & 432.6 & 64.3 & 112.3 & 87 & 8.8 & 8.5 & 8.2 \\
\hline
\end{tabular}

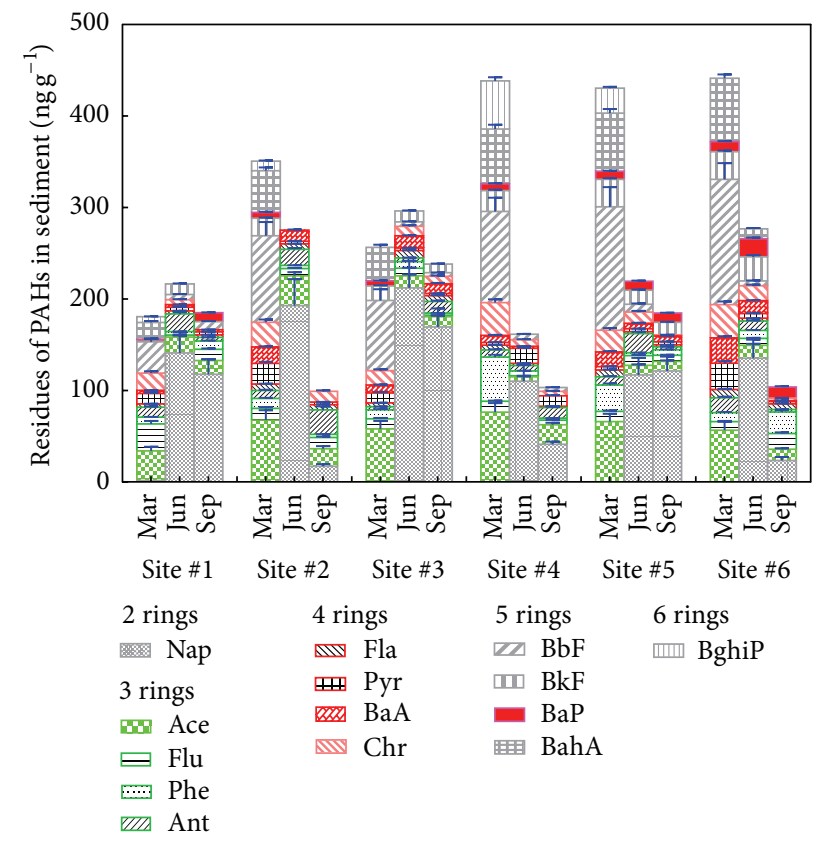

Figure 2: The total average distribution of individual PAHs in sediments from Changdang Lake.

Canada), matrix spikes samples (sediment samples of known PAH levels spiked with a mixture consisting of $1 \mu \mathrm{g}$ each of PAHs), and procedural blanks were used as quality control procedures. Analyses were run in batches of 10 samples plus four quality controls (QCs) including one reagent blank, one matrix blank, one matrix spikes sample, and one random sample in duplicate. The recovery efficiency of PAHs ranged from $89 \%$ to $111 \%$ for HS-5 and from $78 \%$ to $105 \%$ for the spiked samples with relative standard deviation (RSD) $3.2 \%-$ $10.6 \%$. The method detection limits were in the range of $0.5-$ $2.0 \mathrm{ng} \mathrm{g}^{-1}$ dry weight. PAHs standard solution was diluted with acetonitrile, six kinds of concentration of the mixed standard were configured to quantify peak area by establishing a working curve with external standard method, and the correlation of the standard curve was above 0.99 . All of the measurements were performed in triplicate, the results were not corrected according to the percent recovery of HS-5 and spiked samples, and the means were used for the calculations.
2.7. PAHs Source Identification. The isomer ratios of Ant/(Phe + Ant $), \mathrm{Fla} /(\mathrm{Fla}+\mathrm{Pry})$, and $\mathrm{BaA} /(\mathrm{BaA}+\mathrm{Chr})$ were used to identify sources of PAHs in sediments from Changdang Lake. Molecular indices based on ratios of selected PAHs concentrations are commonly applied to identify PAHs from petrogenic and pyrogenic origins $[41,42]$. A ratio of Ant/(Ant + Phe $)<0.10$ indicates dominance of petroleum, while $a>$ 0.10 ratio suggests combustion. Meanwhile, a Fla/(Fla + Pry) $<0.4$ ratio suggests a petroleum source, a ratio between 0.4 and 0.5 indicates liquid fossil fuel combustion, and a $>0.50$ ratio suggests combustion of biomass and coal. Furthermore, it indicates a petroleum source if the ratio of $\mathrm{BaA} /(\mathrm{BaA}$ + Chr) is lower than 0.20 , a source is from combustion coal, grass, and wood if higher than 0.35 , and petroleum combustion (especially liquid fossil fuel, vehicle, and crude oil) if between 0.20 and 0.35 [26].

\section{Results and Discussion}

3.1. Analysis of Environmental Parameters. Five environmental parameters including temperature $(\mathrm{T})$, dissolved oxygen (DO), $\mathrm{pH}$, oxidation-reduction potential (ORP), and conductivity (COND) of the water were measured at the sampling sites in March, June, and September 2013 using SX751 series portable electrochemical meters (San-Xin Instrumentation Inc., Shanghai, China). Environmental parameters measured during the study period are shown in Table 1.

3.2. Concentration of PAHs in Sediments. The residual characteristics of PAHs in the six selected sites are presented in Figure 2. Results showed that the average concentrations of residual PAHs in March, June, and September were $295.28 \mathrm{ng} / \mathrm{g}(180.66 \sim 441.26 \mathrm{ng} / \mathrm{g}) ; 240.91 \mathrm{ng} / \mathrm{g}(161.46 \sim$ $296.23 \mathrm{ng} / \mathrm{g}$ ); and $165.81 \mathrm{ng} / \mathrm{g}(98.98 \sim 231.18 \mathrm{ng} / \mathrm{g}$ ), respectively. Considering spatial distribution, site \#1, which is the intake for drinking water treatment plant, has lower PAHs residues than other sites. In March (dry season), the residual level of PAHs especially the five-ring and six-ring PAHs with more toxicity in sediments was higher than June (wet season) and September (temperate season), which might be related to the coal combustion in winter and spring. Although PAHs from sites \#4 to \#6, which are the inlet and outlet of the lake, are significantly reduced in June and September, the content 


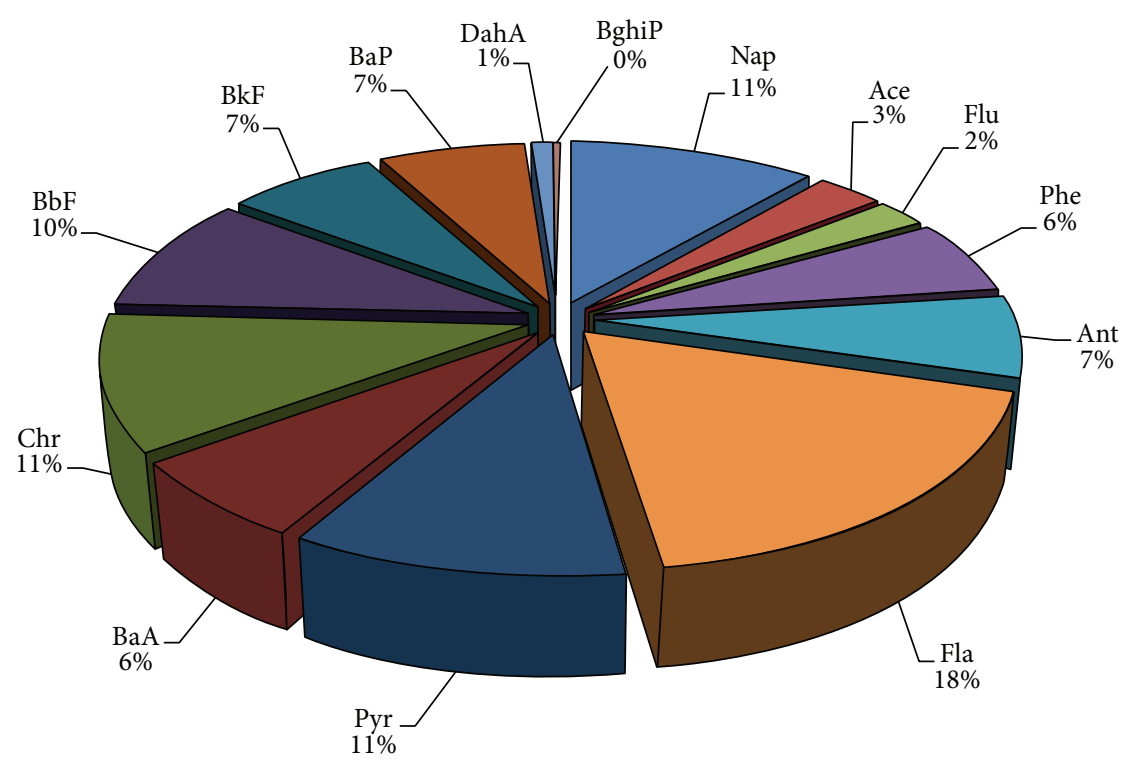

FIgURE 3: The total average distribution of individual PAHs in sediment.

of four-ring and five-ring PAHs was still high; particulary the value of strong carcinogenic benzo[a]pyrene content was observed as higher than $19.68 \mathrm{ng} / \mathrm{g}$ and considerably lower than the corresponding standard value of $150 \mathrm{ng} / \mathrm{g}$ dry weight.

The total percentage $(n=6)$ of 14 PAHs is shown in Figure 3. A clear dominance of middle molecular weight PAHs (Fla 18\%, Pyr 11\%, BaA, 6\%, and Chr 11\%) in respect to low (Nap $11 \%$, Ace $3 \%$, Flu 2\%, Phe 6\%, and Ant $7 \%$ ) and higher molecular weight (BbF 10\%, BkF 7\%, Bap 7\%, DahA $1 \%$, and BghiP $0 \%$ ) was observed. Numerous studies have been reported on PAHs level in the sediments of lakes in China. The average total PAHs concentration in Changdang Lake sediments was less than those levels observed in sediments from Chaohu Lake (908.50 1878.10 ng/g) [13], Taihu Lake (290.00 480.00 ng/g), and Hongfeng Lake (2936.10 $5282.30 \mathrm{ng} / \mathrm{g}$ ) [43], but higher than those data reported from Erhai Lake (31.90 269.00 $\mu \mathrm{g} / \mathrm{g}$ ) [44], Poyang Lake (157.00 $63.20 \mathrm{ng} / \mathrm{g}$ ) [20], and Baiyangdian Lake (189.9 ng/g) [21].

3.3. Source Identification. For source analysis, the diagnostic ratios of Ant/(Ant + Phe $)$, Fla/(Fla + Pyr), and BaA/(BaA + Chr) for the three kinds of water seasons are plotted in Figure 4. The reference standards or threshold values of PAHs ratio for source identification have been discussed by many researchers; the discussion is based on the understanding of the relative discrimination ability (relative thermodynamic stability) of different parent PAHs, the characteristics of different PAH sources, and the changes in PAH composition between source and sediment (the relative stability of different PAH isomers and PAHs from different sources) [26]. The isomeric ratios have been used to assess the pyrogenic or petrogenic sources of PAHs in sediments: Ant/(Ant + Phe), Fla/(Fla + Pyr $)$, and $\mathrm{BaA} /(\mathrm{BaA}+\mathrm{Chr})$; their threshold values and the corresponding source are shown in Table 2 $[14,20,44]$. From Figure 4 and Table 2, we can see that the origins of PAHs in different sampling sites have a great deal of temporal and spatial variability based on three isomer ratios of PAHs. According to the analysis of single ratio of PAHs, the ratios of Ant/(Ant + Phe) were higher than 0.10; this indicates that the main PAHs source was pyrogenic source [14]. The ratios of Fla/(Fla + Pyr) at sites M1, M2, M3, M6, and J6 were lower than 0.40 ; this indicates that the main $\mathrm{PAH}$ source may originate from petroleum products $[45,46]$; those at sites J1, J4, J5, S1, S5, and S6 were between 0.40 and 0.50 , indicating that they originated from petroleum combustion; the other sites were higher than 0.50; this implies that the $\mathrm{PAH}$ source may be biomass combustion (grass, wood) or coal combustion $[20,44]$.

The ratios of $\mathrm{BaA} /(\mathrm{BaA}+\mathrm{Chr})$ at sites $\mathrm{M} 1, \mathrm{M} 4, \mathrm{~S} 2$, and S4 were lower than 0.20 , indicating that the main PAH source may originate from petroleum products; those of sites J4 and J5 were between 0.20 and 0.35 , indicating that they originated from petroleum combustion; the other sites were higher than 0.35; this implies that the PAH source could be biomass combustion (grass, wood) or coal combustion [14].

The results mentioned above showed that some of the sources at some sites were contradictory; this phenomenon has also been observed by other scientists [21], so the source identification using three ratios of PAHs can avoid the misleading when using a single ratio of PAHs. After a comprehensive analysis, the dominative pollution source of PAHs at sites S4, M1, and M4 mainly comes from petroleum products; the PAHs source at sites J1, J4, J5, S1, S5, and S6 may be petroleum combustion; other sites mainly come from biomass combustion (grass, wood) or coal combustion. From the point of spatial and temporal variation, the main pollution sources of PAHs at site \#1 (the intake for the drinking water treatment plant) and site \#4 (the lake outlet of Changdang Lake) derived from the mixed source of petroleum production and petroleum combustion sources; this was related to the channel in the lake near the two sites; the leakage and burn of gasoline from the ship resulted in the accumulated in the sediment. The source of PAHs in both site \#5 and site \#6 


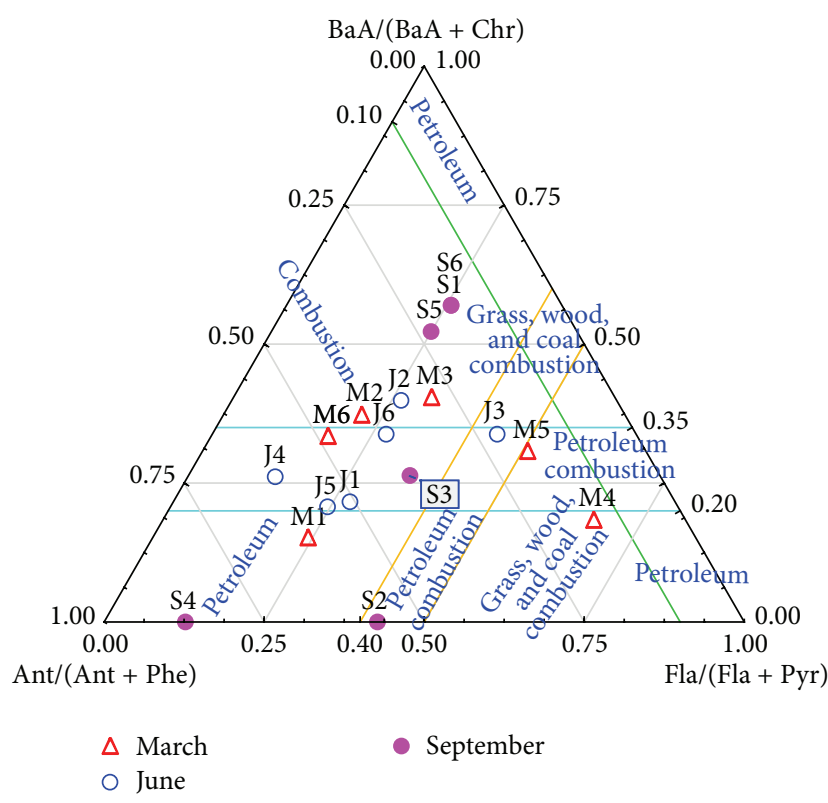

Figure 4: Isomer ratios of Ant/(Ant + Phe), Fla/(Fla + Pyr), and $\mathrm{BaA} /(\mathrm{BaA}+\mathrm{Chr})$.

mainly came from the mixed combustion source of biomass and petroleum, the two sites located at the lake inlet of two rivers into the lake, and the composition of PAHs was affected by the inflow water of the rivers, which mainly received the combustion sources of biomass and petroleum because the river passed though the village and highways. Site \#2 and site \#3 located at the heart of lake; the source of PAHs dominated by the PAHs derived from the combustion of biomass or coal during different water seasons; this might be attributed to the river inputs and the dry and wet deposition; the latter was also impacted by the anthropogenic activities like straw burning before rice cultivation and postharvesting and heating with coke oven in winter and spring. These results are in line with the actual situation of the scene, and they also accord with people's understanding on the source apportionment [13,20, 44]. Therefore, this source identification method is effective.

3.4. Redundancy Analysis. The sampling sites, environmental factors, and PAHs residual concentration could be well divided into three groups (ellipse lines in Figure 5) based on the redundancy analysis. The predominant environmental factors and the dominant residual PAHs at different sampling sites were determined from the length of the arrows in Figure 5. As Table 3 shows, the eigenvalues of the first two RDA axes were 0.6264 and 0.0498 , respectively. The correlation coefficient between two species axes was -0.0420 , showing that these axes were poorly correlated. The correlation coefficient of the two environmental axes was 0 , indicating that they were perpendicular to each other. This demonstrates that the ordination results can reflect the relationships between PAHs and environmental factors in the study area.

Group I was associated with the sampling sites in March (dry season), which had high content of Ace, BaA, Chr, Flu,
Phe, Pyr, Fla, BbF, BkF, BaP, DahA, and BghiP with 3- to 6ring PAHs and lower contents of Nap and Ant in these sites. From the projection point of PAHs species arrows falling in the opposite direction of the arrows of T, DO, and ORP, we can deduce their significant negative correlation. Besides the variation of pollutant source type in spring or winter as compared to other seasons, the environmental conditions of cold weather and low ORP value in March may affect the degradation and occurrence characteristics of PAHs in water body. Meanwhile, $\mathrm{pH}$ showed obvious positive correlation with the first species axis with 3- to 6-ring PAHs in these sites in March $(r=0.4280)$; it implied that high $\mathrm{pH}$ was conducive to the residue of these PAHs in sediment.

Group II was associated with the sampling sites in June (wet season), which had higher content of Nap and Ant with 2- to 3-ring PAHs as compared to March (dry season). From the projection point of PAHs species arrows falling in the same direction of the arrows of T, DO, and ORP, we can speculate their significant positive correlation, and the phenomenon of low-ring PAHs predominating in these sampling sites may be related to the variation of the environmental condition of high temperature and high ORP value in June, which is conducive to the residue and occurrence of Nap and Ant in sediments. The distribution characteristics of sampling sites in September (temperate season) have a high similarity with those sites in June (wet season). But the sampling sites in September were subjected to greater impact from the COND, so we divided the September sites into group III. The relationship between PAHs and the first species axis was more obvious than that between PAHs and the second species axis (Table 3).

The correlation coefficients between Ace, BbF, BkF, DahA, and BghiP and the first species axis were 0.4147, 0.9068, $0.9133,0.9620$, and 0.6439 , respectively. It can approximate the correlation between PAHs and environmental variable (e.g., $\mathrm{T}$ and ORP) by the distance of the perpendicular projection point of the species arrow-tips (e.g., PAHs) onto the environmental variable arrows (e.g., $\mathrm{T}$ and $\mathrm{ORP}$ ) from the coordinate origin (zero point). The longer the distance, the higher the correlation. If the projection point lies in the opposite direction (e.g., BbF, BkF, DahA, and BghiP), then their correlation is negative.

As shown in Table 4, three environmental parameters (T, DO, and ORP) were negatively correlated with the first species axis. The correlation between the first species axis and $\mathrm{T}$ was the most significant $(r=-0.9168)$. The other factors had positive correlation with the first species axis; $\mathrm{pH}$ was the most remarkable positive correlation factor $(r$ $=0.4283$ ). Most of the factors showed negative correlation with the second species axis; DO was the most remarkable correlation factor $(r=0.4435)$. From the arrow-line lengths and the correlation analysis of environmental indexes and the first two species axes, we can infer that the main factors impacting PAHs distribution are $\mathrm{T}, \mathrm{DO} \mathrm{pH}$, and ORP while COND had secondary impacts on PAHs distribution.

3.5. Ecological Risk Assessment. As China has not yet set an environmental standard for PAHs in sediment. Therefore, in 
TABLE 2: The reference standard of PAHs source identification for ratio method.

\begin{tabular}{|c|c|c|c|c|}
\hline & Petrogenic origin & Petroleum combustion & Combustion of biomass and coal & Reference \\
\hline Ant/(Ant + Phe $)$ & $<0.10$ & $>0.10$ & $>0.10$ & {$[14]$} \\
\hline Group of sites & \multicolumn{4}{|c|}{ All of the sampling sites } \\
\hline $\mathrm{Fla} /(\mathrm{Fla}+\mathrm{Pyr})$ & $<0.40$ & $0.50>R>0.40$ & $>0.50$ & {$[20,21]$} \\
\hline Group of sites & $\mathrm{M} 1, \mathrm{M} 2, \mathrm{M} 3, \mathrm{M} 6$, and J6 & $\mathrm{J} 1, \mathrm{~J} 4, \mathrm{~J} 5, \mathrm{~S} 1, \mathrm{~S} 5$, and S6 & Other sampling sites & \\
\hline $\mathrm{BaA} /(\mathrm{BaA}+\mathrm{Chr})$ & $<0.20$ & $0.35>R>0.20$ & $>0.35$ & {$[14]$} \\
\hline $\begin{array}{l}\text { Group of sites } \\
\text { S2 and S4 }\end{array}$ & M1, M4 & J4 and J5 & Other sampling sites & \\
\hline
\end{tabular}

TABLE 3: Eigenvalues for RDA axis and environmental indexes correlations.

\begin{tabular}{|c|c|c|c|c|c|}
\hline Axes & 1 & 2 & 3 & 4 & Total variance \\
\hline Eigenvalues & 0.6264 & 0.0498 & 0.0856 & 0.0697 & 1.0000 \\
\hline Explained variation (cumulative) & 62.64 & 67.62 & 76.18 & 83.15 & \\
\hline Pseudocanonical correlation & 0.9696 & 0.7022 & 0.0000 & 0.0000 & \\
\hline Explained fitted variation (cumulative) & 88.90 & 95.97 & & & \\
\hline
\end{tabular}

TABLE 4: Correlation coefficients among environmental indexes, PAHs and RDA ordination axes.

\begin{tabular}{lcccc}
\hline $\begin{array}{l}\text { Environmental } \\
\text { parameters and }\end{array}$ & Axis 1 & Axis 2 & Axis 3 & Axis 4 \\
PAHs & & & & \\
\hline T & -0.9168 & 0.1971 & -0.0032 & -0.0100 \\
DO & -0.1480 & 0.4435 & -0.1041 & -0.0849 \\
COND & -0.0670 & -0.4215 & -0.0379 & 0.0119 \\
Eh & -0.4481 & 0.4787 & 0.1015 & 0.0695 \\
pH & 0.4283 & 0.0485 & -0.1642 & -0.0993 \\
Nap & -0.9123 & 0.2484 & 0.1718 & 0.1317 \\
Ace & 0.8275 & -0.1742 & -0.0995 & -0.0572 \\
Flu & 0.5027 & -0.2518 & 0.2936 & 0.1881 \\
Phe & 0.7625 & 0.1703 & 0.1589 & 0.1373 \\
Ant & -0.1376 & 0.0238 & -0.4362 & -0.4289 \\
Fla & 0.4212 & -0.0613 & -0.4515 & -0.0190 \\
Pyr & 0.4617 & -0.0883 & -0.1105 & -0.2645 \\
BaA & 0.5113 & 0.4609 & -0.2460 & 0.4079 \\
Chr & 0.6575 & 0.1510 & -0.6108 & -0.2567 \\
BbF & 0.9120 & 0.0016 & -0.0825 & 0.0379 \\
BkF & 0.5064 & 0.4055 & -0.5969 & 0.4309 \\
BaP & 0.5176 & 0.2502 & 0.2251 & 0.6458 \\
DahA & 0.9604 & 0.0891 & -0.1500 & 0.0031 \\
BghiP & 0.7529 & -0.0046 & 0.0493 & -0.1962 \\
\hline & & & &
\end{tabular}

this study, PAHs associated risk in sediments was assessed by applying the "US Sediment Quality Guidelines" (SQGs) $[36,42]$. SQGs provide two effects-based sediment guideline values: effects range-low (ERL) and effects range-median (ERM), which quantitatively assess the adverse biological effects in sediments [45]. These two values establish three concentration ranges for PAHs. PAHs will not be harmful

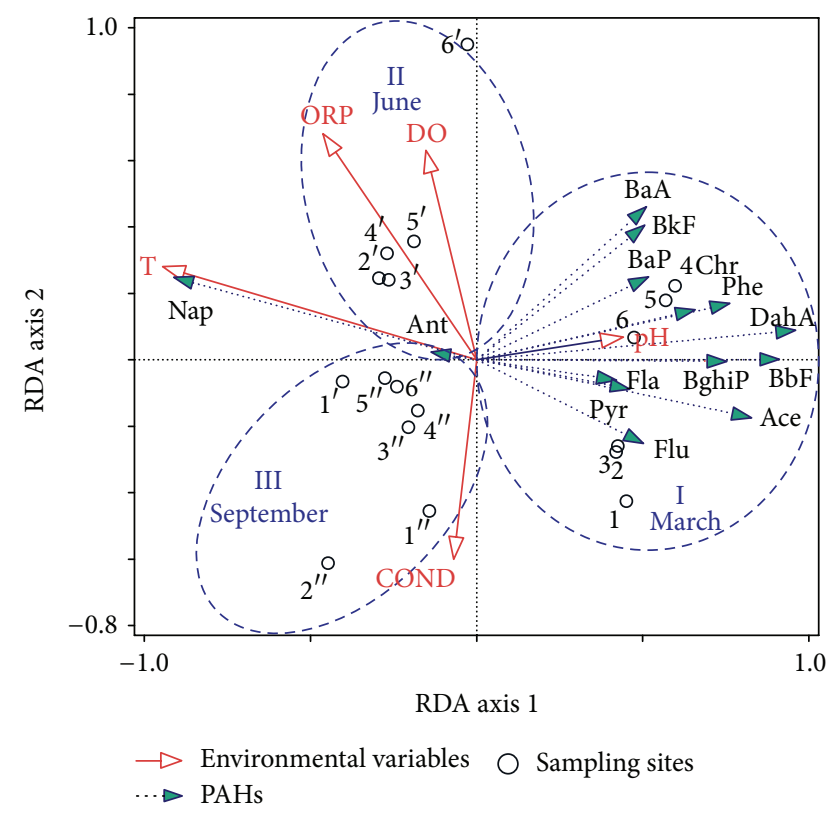

FIGURE 5: Redundancy analysis (RDA) plot of the relationship between environmental parameters and PAHs in March (dry season), June (wet season), and September (temperate season).

to the environment and its biota when their concentrations are lower than ERL; while the concentrations are higher than ERM, PAHs will show negative impacts frequently. PAHs with concentrations between ERL and ERM are considered to be harmful occasionally $[36,45]$.

Concentrations of $\sum$ PAHs in sediments in all sites were less than the ERL value of $4749 \mathrm{ng} / \mathrm{g} \mathrm{dw}$ (Table 5). But in June, there was one constituent that might occasionally exceed the ERL and pose biological impairment. For example, the maximum concentration of naphthalene (Nap) was $212.11 \mathrm{ng} / \mathrm{g} \mathrm{dw}$ in June and $169.41 \mathrm{ng} / \mathrm{g}$ dw in September, which exceeded the 
TABLE 5: Standard pollution criteria of PAH concentrations for sediment (ng/g dw) (ERL: effects range-low, ERM: effects range-median, and NA: not available).

\begin{tabular}{|c|c|c|c|c|c|c|c|c|}
\hline \multirow{3}{*}{ PAHs } & \multirow{2}{*}{\multicolumn{2}{|c|}{ Guidelines }} & \multicolumn{6}{|c|}{ This study } \\
\hline & & & \multicolumn{2}{|c|}{ March } & \multicolumn{2}{|c|}{ June } & \multicolumn{2}{|c|}{ September } \\
\hline & ERL & ERM & Average & Max & Average & Max & Average & Max \\
\hline Nap & 160 & 2100 & 0.25 & 1.54 & 151.35 & 212.11 & 61.96 & 169.41 \\
\hline Ace & 44 & 640 & 14.34 & 76.28 & 15.455 & 32.59 & 14.7 & 21.21 \\
\hline Flu & 19 & 540 & 19.11 & 29.6 & 6.28 & 10.75 & 9.66 & 17.08 \\
\hline Phe & 240 & 1500 & 19.11 & 48.29 & 5.21 & 8.78 & 10.53 & 23.62 \\
\hline Ant & 853 & 1100 & 9.33 & 16.29 & 13.08 & 20.93 & 5.82 & 26.78 \\
\hline Fla & 600 & 5100 & 6.09 & 9.08 & 4.08 & 8.07 & 3.31 & 6.43 \\
\hline Pyr & 665 & 2600 & 13.38 & 28.74 & 5.73 & 16.42 & 5.64 & 11.26 \\
\hline $\mathrm{BaA}$ & 261 & 1600 & 13.58 & 27.8 & 8.48 & 14.23 & 2.5 & 10.66 \\
\hline Chr & 384 & 2800 & 26.21 & 36.35 & 8.56 & 16.19 & 2.95 & 11.69 \\
\hline $\mathrm{BbF}$ & 320 & 1880 & 96.17 & 136.84 & 5.05 & 8.53 & 1.38 & 8.85 \\
\hline $\mathrm{BkF}$ & 280 & 1620 & 19.82 & 30.28 & 13.05 & 26.39 & 4.61 & 13.84 \\
\hline $\mathrm{BaP}$ & 430 & 1600 & 6.91 & 10.99 & 4.9 & 19.68 & 7.38 & 12.11 \\
\hline DahA & 63.4 & 260 & 48.83 & 69.28 & 1.83 & 10.99 & NA & NA \\
\hline BghiP & 430 & 1600 & 16.13 & 52.69 & NA & NA & NA & NA \\
\hline$\sum$ PAHs & 4749 & 24940 & 309.31 & 574.05 & 243.08 & 405.66 & 130.5 & 332.94 \\
\hline
\end{tabular}

ERL value of $160 \mathrm{ng} / \mathrm{g} \mathrm{dw}$. In March acenaphthylene (Ace) and fluorene (Flu) maximum concentration was $76.28 \mathrm{ng} / \mathrm{g} \mathrm{dw}$ and $29.06 \mathrm{ng} / \mathrm{g} \mathrm{dw}$, respectively, which exceeded the ERL values of $44 \mathrm{ng} / \mathrm{g} \mathrm{dw}$ and $19 \mathrm{ng} / \mathrm{g} \mathrm{dw}$. These results values indicated that the probability of ecological risk associated with these PAHs was below $10 \%$ and the adverse biological toxicity effect would occur occasionally. SQGs have been used by several researchers around the world, such as Cardellicchio et al., who used this approach to provide possible ecotoxicological risk estimations for benthic organisms at Mar Piccolo in Taranto, southern Italy [46], and Binelli et al., who compared SQGs for toxicity assessment in the Bay of Bengal in India [47].

\section{Conclusion}

PAHs were systematically investigated in sediments from Changdang Lake. The results indicated that average $\sum$ PAHs concentration in March (dry season) was higher $(295.28 \mathrm{ng} / \mathrm{g} \mathrm{dw})$ than those in June (wet season) (240.91 ng/g) and September (temperate season) $(165.81 \mathrm{ng} / \mathrm{g} \mathrm{dw})$. Sources of PAHs were mainly from the mixed combustion sources of biomass and petroleum, and the origins of PAHs in different sampling sites have a great deal of temporal and spatial variability during different water seasons. This study's results highlighted that environmental parameters like temperature, dissolved oxygen, $\mathrm{pH}$, and conductivity played a more significant role in controlling the distributions of PAHs in sediments. By comparing the present study results with the US SQGs values, PAHs associated risk is not high in the sediments from Changdang Lake. However further attention should be paid and preventive measures should be taken to save the lake from further PAHs contamination. This study's results will provide useful information to the local administration about PAHs level in sediments from Changdang Lake.

\section{Conflict of Interests}

The authors declare that there is no conflict of interests regarding the publication of this paper.

\section{Acknowledgments}

This work was supported by the National Natural Science Foundation of China (41371307, 51509129), the Opening Funding of State Key Laboratory of Pollution Control and Resource Reuse (PCRRF12010), the State Key Laboratory of Soil and Sustainable Agriculture (Institute of Soil Science, Chinese Academy of Sciences Foundation (0812201228)), and a Project Funded by the Priority Academic Program Development of Jiangsu Higher Education Institutions (PAPD).

\section{References}

[1] E. Lipiatou, I. Tolosa, R. Simó et al., "Mass budget and dynamics of polycyclic aromatic hydrocarbons in the Mediterranean Sea," Deep-Sea Research Part II: Topical Studies in Oceanography, vol. 44, no. 3-4, pp. 881-905, 1997.

[2] P. Baumard, H. Budzinski, and P. Garrigues, "Polycyclic aromatic hydrocarbons in sediments and mussels of the Western Mediterranean sea," Environmental Toxicology and Chemistry, vol. 17, no. 5, pp. 765-776, 1998.

[3] X. Martínez-Lladó, O. Gibert, V. Martí et al., "Distribution of polycyclic aromatic hydrocarbons (PAHs) and tributyltin (TBT) in Barcelona harbour sediments and their impact on 
benthic communities," Environmental Pollution, vol. 149, no. 1, pp. 104-113, 2007.

[4] Z. D. Wang, M. Fingas, Y. Y. Shu et al., "Quantitative characterization of PAHs in burn residue and soot samples and differentiation of pyrogenic PAH1 from petrogenic PAHs-the 1994 mobile burn study," Environmental Science and Technology, vol. 33, no. 18, pp. 3100-3109, 1999.

[5] B. J. Finlayso-Pitts and J. J. N. Pitts, “Tropospheric air pollution ozone, airborne toxics, polycyclic aromatic hydrocarbons and particles," Science, vol. 276, no. 5315, pp. 1045-1051, 1997.

[6] Q. X. Zhou, F. X. Kong, and L. Zhu, Ecotoxicology, Science Press, Beijing, China, 2004 (Chinese).

[7] Y. Liu, L. Chen, Q.-H. Huang, W.-Y. Li, Y.-J. Tang, and J.-F. Zhao, "Source apportionment of polycyclic aromatic hydrocarbons (PAHs) in surface sediments of the Huangpu River, Shanghai, China," Science of the Total Environment, vol. 407, no. 8, pp. 2931-2938, 2009.

[8] C. Riccardi, P. D. Filippo, D. Pomata, M. D. Basilio, S. Spicaglia, and F. Buiarelli, "Identification of hydrocarbon sources in contaminated soils of three industrial areas," Science of the Total Environment, vol. 450-451, pp. 13-21, 2013.

[9] M. A. Khairy, M. Kolb, A. R. Mostafa, A. EL-Fiky, and M. Bahadir, "Risk assessment of polycyclic aromatic hydrocarbons in a Mediterranean semi-enclosed basin affected by human activities (Abu Qir Bay, Egypt)," Journal of Hazardous Materials, vol. 170, no. 1, pp. 389-397, 2009.

[10] J. Beyer, G. Jonsson, C. Porte, M. M. Krahn, and F. Ariese, "Analytical methods for determining metabolites of polycyclic aromatic hydrocarbon (PAH) pollutants in fish bile: a review," Environmental Toxicology and Pharmacology, vol. 30, no. 3, pp. 224-244, 2010.

[11] M. Saha, A. Togo, K. Mizukawa et al., "Sources of sedimentary PAHs in tropical Asian waters: differentiation between pyrogenic and petrogenic sources by alkyl homolog abundance," Marine Pollution Bulletin, vol. 58, no. 2, pp. 189-200, 2009.

[12] R. Lohmann, E. Jurado, M. B. E. B. Q. Pilson, and J. Dachs, "Oceanic deep water formation as a sink of persistent organic pollutants," Geophysical Research Letters, vol. 33, no. 22, pp. 735$742,2006$.

[13] N. Qin, W. He, X. Z. Kong, and X. L. Zhao, "Distribution, partitioning and sources of polycyclic aromatic hydrocarbons in the water-SPM-sediment system of Lake Chaohu. China," Science of the Total Environment, vol. 34, no. 4, pp. 445-456, 2011.

[14] J. I. Wan, A. F. Roth, A. O. Bailey, and N. G. Davis, "Palmitoylated proteins: purification and identification," Nature Protocols, vol. 2, no. 7, pp. 1573-1584, 2007.

[15] W. T. Wang, S. L. M. Simonich, M. Xue et al., "Concentrations, sources and spatial distribution of polycyclic aromatic hydrocarbons in soils from Beijing, Tianjin and surrounding areas, North China," Environmental Pollution, vol. 158, no. 5, pp. 12451251, 2010.

[16] D. W. Connel, D. W. Hawker, M. J. Warne, and P. P. Vowles, "Polycyclic aromatic hydrocarbons (PAHs)," in Introduction into Environmental Chemistry, K. McCombs and A. W. Starkweather, Eds., CRC Press LLC, Boca Raton, Fla, USA, 1997.

[17] W. E. Pereira, F. D. Hostettler, and J. B. Rapp, "Distributions and fate of chlorinated pesticides, biomarkers and polycyclic aromatic hydrocarbons in sediments along a contamination gradient from a point-source in San Francisco Bay, California," Marine Environmental Research, vol. 41, no. 3, pp. 299-314, 1996.
[18] R. Boonyatumanond, G. Wattayakorn, A. Togo, and H. Takada, "Distribution and origins of polycyclic aromatic hydrocarbons (PAHs) in riverine, estuarine, and marine sediments in Thailand," Marine Pollution Bulletin, vol. 52, no. 8, pp. 942-956, 2006.

[19] E. Manoli, C. Samara, I. Konstantinou, and T. Albanis, "Polycyclic aromatic hydrocarbons in the bulk precipitation and surface waters of Northern Greece," Chemosphere, vol. 41, no. 12, pp. 1845-1855, 2000.

[20] M. Lu, D.-C. Zeng, Y. Liao, and B. Tong, "Distribution and characterization of organochlorine pesticides and polycyclic aromatic hydrocarbons in surface sediment from Poyang Lake, China," Science of the Total Environment, vol. 433, pp. 491-497, 2012.

[21] G. Hu, X. Luo, F. Li et al., "Organochlorine compounds and polycyclic aromatic hydrocarbons in surface sediment from Baiyangdian Lake, North China: concentrations, sources profiles and potential risk," Journal of Environmental Sciences, vol. 22, no. 2, pp. 176-183, 2010.

[22] I. C. T. Nisbet and P. K. LaGoy, "Toxic equivalency factors (TEFs) for polycyclic aromatic hydrocarbons (PAHs)," Regulatory Toxicology and Pharmacology, vol. 16, no. 3, pp. 290-300, 1992.

[23] Committee on Pyrene and Selected Analogues and Board on Toxicology and Environmental Health Hazards, Polycyclic Aromatic Hydrocarbons, Evaluation of Sources and Effects, National Service Center for Environmental Publications, Washington, DC, USA, 1983.

[24] W. L. Lockhart, R. Wagemann, B. Tracey, D. Sutherland, and D. J. Thomas, "Presence and implications of chemical contaminants in the freshwaters of the Canadian Arctic," Science of the Total Environment, vol. 122, no. 1-2, pp. 165-243, 1992.

[25] M. P. Zakaria, H. Takada, S. Tsutsumi et al., "Distribution of polycyclic aromatic hydrocarbons (PAHs) in rivers and estuaries in Malaysia: a widespread input of petrogenic PAHs," Environmental Science \& Technology, vol. 36, no. 9, pp. 19071918, 2002.

[26] M. B. Yunker, R. W. Macdonald, R. Vingarzan, R. H. Mitchell, D. Goyette, and S. Sylvestre, "PAHs in the Fraser River basin: a critical appraisal of PAH ratios as indicators of PAH source and composition," Organic Geochemistry, vol. 33, no. 4, pp. 489-515, 2002.

[27] S. M. Bamforth and I. Singleton, "Bioremediation of polycyclic aromatic hydrocarbons: current knowledge and future directions," Journal of Chemical Technology \& Biotechnology, vol. 80, no. 7, pp. 723-736, 2005.

[28] C. R. Rao, "The use and interpretation of principal component analysis in applied research," Sankhyā A, vol. 26, no. 4, pp. 329358, 1964.

[29] A. M. Kipopoulou, E. Manoli, and C. Samara, "Bioconcentration of polycyclic aromatic hydrocarbons in vegetables grown in an industrial area," Environmental Pollution, vol. 106, no. 3, pp. 369-380, 1999.

[30] M. Nadal, M. Schuhmacher, and J. L. Domingo, "Levels of PAHs in soil and vegetation samples from Tarragona county, Spain," Environmental Pollution, vol. 132, no. 1, pp. 1-11, 2004.

[31] J. Lepš and P. Šmilauer, Multivariate Analysis of Ecological Data Using CANOCO, Cambridge University Press, Cambridge, UK, 2003.

[32] C. J. F. ter Braak and P. Šmilauer, CANOCO Reference Manual and CanoDraw for Windows User's Guide: Software for 
Canonical Community Ordination (Version 4.5), Microcomputer Power, New York, NY, USA, 2002.

[33] S. Ray, P. S. Khillare, T. Agarwal, and V. Shridhar, "Assessment of PAHs in soil around the International Airport in Delhi, India," Journal of Hazardous Materials, vol. 156, no. 1-3, pp. 9-16, 2008.

[34] J. Zhang, J. Dai, H. Chen, X. Du, W. Wang, and R. Wang, "Petroleum contamination in groundwater/air and its effects on farmland soil in the outskirt of an industrial city in China," Journal of Geochemical Exploration, vol. 118, pp. 19-29, 2012.

[35] E. R. Long, D. D. Macdonald, S. L. Smith, and F. D. Calder, "Incidence of adverse biological effects within ranges of chemical concentrations in marine and estuarine sediments," Environmental Management, vol. 19, no. 1, pp. 81-97, 1995.

[36] D. D. MacDonald, C. G. Ingersoll, and T. A. Berger, "Development and evaluation of consensus-based sediment quality guidelines for freshwater ecosystems," Archives of Environmental Contamination and Toxicology, vol. 39, no. 1, pp. 20-31, 2000.

[37] K. Pozo, G. Perra, V. Menchi et al., "Levels and spatial distribution of polycyclic aromatic hydrocarbons (PAHs) in sediments from Lenga Estuary, central Chile," Marine Pollution Bulletin, vol. 62, no. 7, pp. 1572-1576, 2011.

[38] C.-W. Chen and C.-F. Chen, "Distribution, origin, and potential toxicological significance of polycyclic aromatic hydrocarbons (PAHs) in sediments of Kaohsiung Harbor, Taiwan," Marine Pollution Bulletin, vol. 63, no. 5-12, pp. 417-423, 2011.

[39] A. O. Barakat, A. Mostafa, T. L. Wade, S. T. Sweet, and N. B. El Sayed, "Distribution and characteristics of PAHs in sediments from the Mediterranean coastal environment of Egypt," Marine Pollution Bulletin, vol. 62, no. 9, pp. 1969-1978, 2011.

[40] W. Jiao, T. Wang, J. S. Khim et al., "PAHs in surface sediments from coastal and estuarine areas of the northern Bohai and Yellow Seas, China," Environmental Geochemistry and Health, vol. 34, no. 4, pp. 445-456, 2012.

[41] J.-O. Cheng, F.-C. Ko, C.-L. Lee, and M.-D. Fang, "Air-water exchange fluxes of polycyclic aromatic hydrocarbons in the tropical coast, Taiwan," Chemosphere, vol. 90, no. 10, pp. 26142622, 2013.

[42] W. X. Liu, J. L. Chen, X. M. Lin, and S. Tao, "Distribution and characteristics of organic micropollutants in surface sediments from Bohai Sea," Environmental Pollution, vol. 140, no. 1, pp. 48, 2006.

[43] J.-Y. Guo, F.-C. Wu, L. Zhang et al., "Screening level of PAHs in sediment core from Lake Hongfeng, Southwest China," Archives of Environmental Contamination and Toxicology, vol. 60, no. 4, pp. 590-596, 2011.

[44] J. Guo, Z. Liang, H. Liao, Z. Tang, X. Zhao, and F. Wu, "Sedimentary record of polycyclic aromatic hydrocarbons in Lake Erhai, Southwest China," Journal of Environmental Sciences, vol. 23, no. 8, pp. 1308-1315, 2011.

[45] E. R. Long and D. D. MacDonald, "Recommended uses of empirically derived, sediment quality guidelines for marine and estuarine ecosystems," Human and Ecological Risk Assessment, vol. 4, no. 5, pp. 1019-1039, 1998.

[46] N. Cardellicchio, A. Buccolieri, S. Giandomenico, L. Lopez, F. Pizzulli, and L. Spada, "Organic pollutants (PAHs, PCBs) in sediments from the Mar Piccolo in Taranto (Ionian Sea, Southern Italy)," Marine Pollution Bulletin, vol. 55, no. 10-12, pp. 451-458, 2007.

[47] A. Binelli, S. K. Sarkar, M. Chatterjee et al., "A comparison of sediment quality guidelines for toxicity assessment in the Sunderban wetlands (Bay of Bengal, India)," Chemosphere, vol. 73, no. 7, pp. 1129-1137, 2008. 

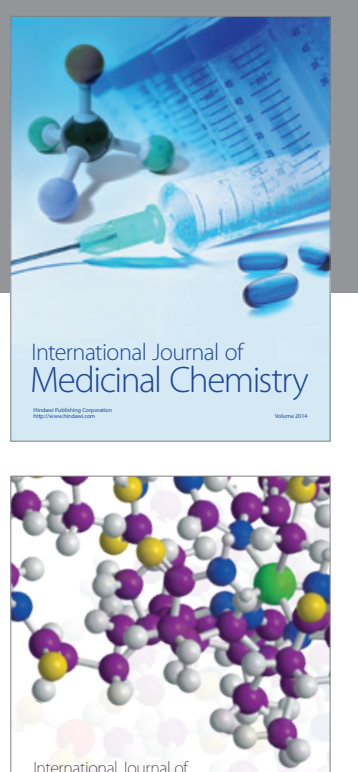

Carbohydrate Chemistry

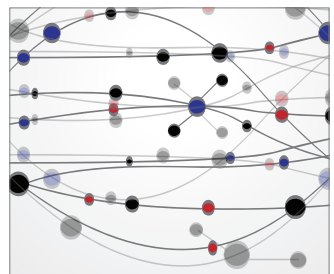

The Scientific World Journal
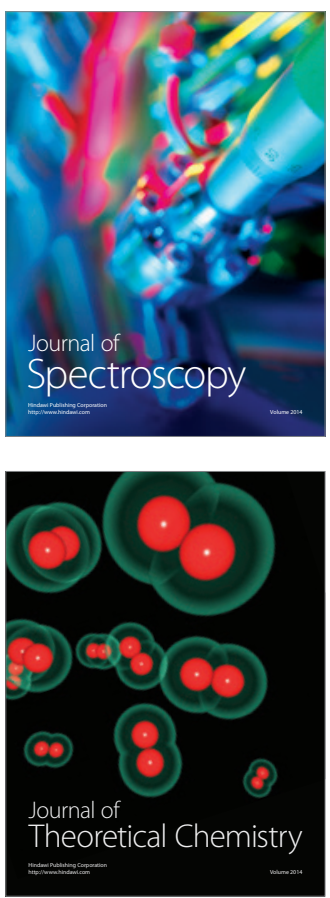
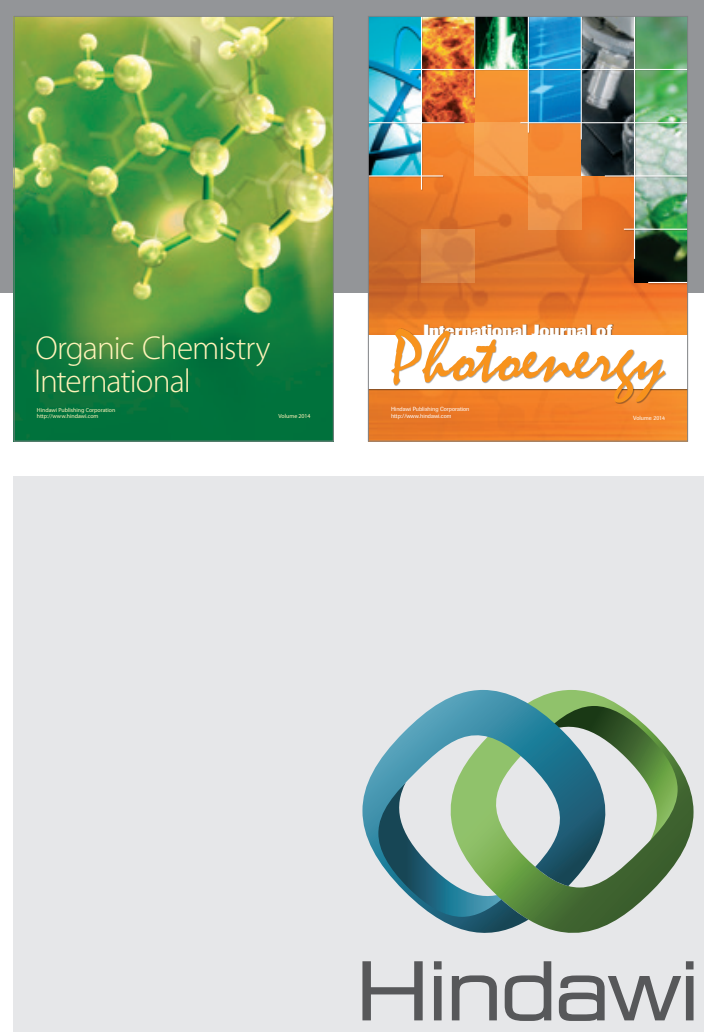

Submit your manuscripts at

http://www.hindawi.com

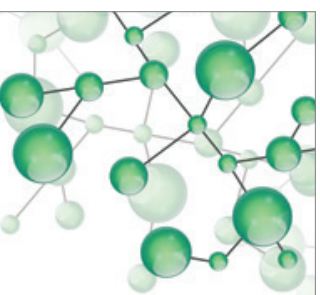

International Journal of

Inorganic Chemistry

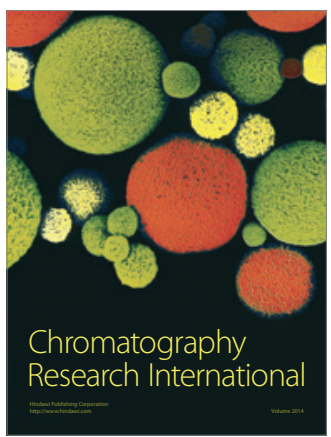

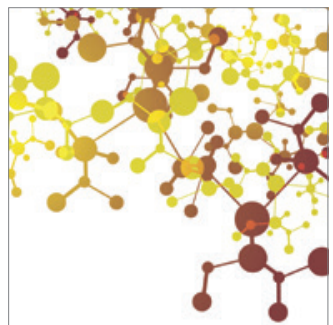

Applied Chemistry
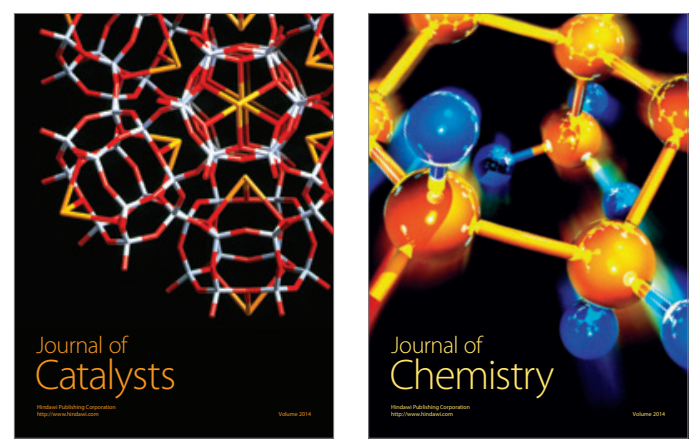
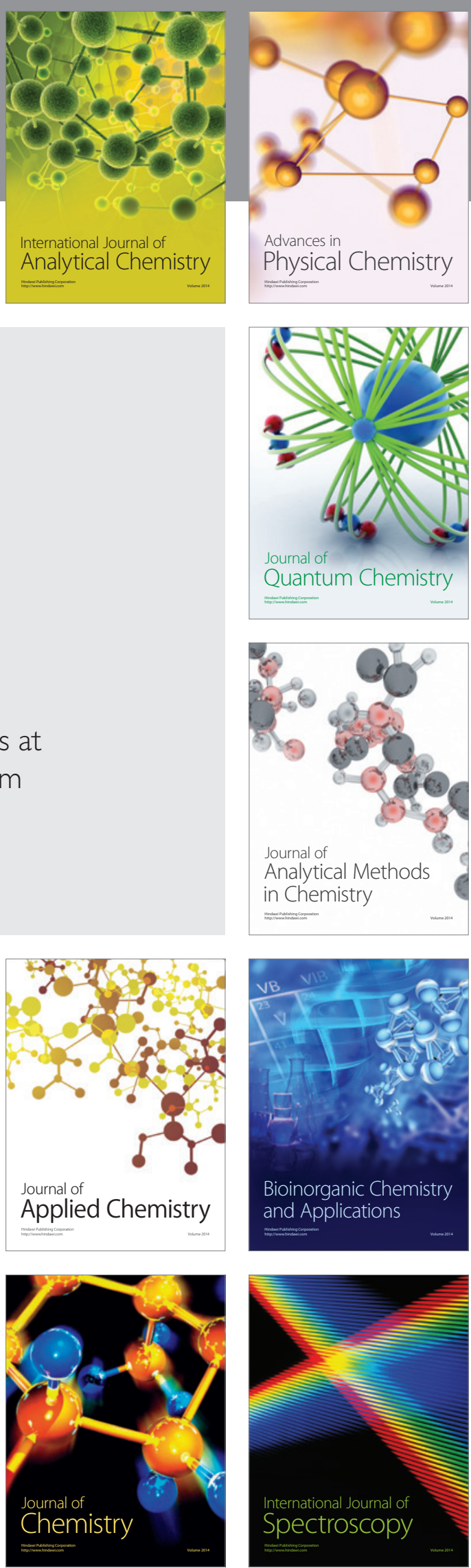